\title{
An Overlooked Cost of Achieving A Participatory Environment
}

Academic librarianship has often seemed to muddle onward seemingly undisturbed by "gut" issues which transcend the perennial concern with the budget and the love-hate relationship with new technologies. Recently, however, evidence has mounted which clearly indicates a growing dissatisfaction among the rank and file of university librarians with their status within the academic community and within the library itself. Through a number of channels, they are making it clear that they are determined to have a larger piece of the action, specifically, the salary and fringe benefits of full faculty status and a larger role in the decisions which affect their professional lives. It is the cost of achieving these goals with which this editorial is concerned.

While it is clear that increasing numbers of university librarians, including some at the top, are rallying to the position that a truly participatory environment can lead to a new birth of professional freedom, growth, and productivity, there seems to be little clear understanding that achieving these goals will require a radical restructuring of the library, not just a cosmetic modification through a proliferation of committees and task forces. As ego satisfying as this approach may be to those who previously have been denied a role in the determination of programs and goals and the solution of problems, the fact remains that it leaves the traditional bureaucratic power structure of the library essentially unchanged and with relationships between professionals still largely determined by their relative positions within it. Still intact are the layers of "supervisors" in the middle level of the library hierarchy. This stands in stark contrast to the results of recent research which has clearly shown that the morale and productivity of the knowledge worker are the highest where the amount of direct supervision is the least. Until the implications of this basic proposition of participatory management theory are clearly understood and faced up to, the achievement of faculty status and professorial titles will be a somewhat hollow victory. For what meaning is there to the professorial title if its holder still "reports to" a supervisor and his performance is evaluated in much the same manner as the classified staff? This is an irony often pointed to by the established members of the faculty club.

Reducing the middle level bureaucracy will not be an easy task. In the first place, the traditional reward system which ties salary and status to the level of administrative or supervisory responsibility and which has been partly responsible for its creation will have to be severely modified. If the system values most the bureaucratic accomplishments, it will produce bureaucrats in abundance-whether they serve any useful function or not.

Secondly, the aspirations of many within the profession will have to be raised. Finally, the middle level of the library hierarchy tends to be 
staunchly conservative, and its resistance to any proposal which would radically affect its power and authority will be vigorous for the obvious and understandable reason that it has a major investment in the status quo.

Given these conditions, severely reducing the middle level bureaucracy in order to help create a working environment in which superior/inferior is more a matter of the individual's contribution to the educational mission of the library than the authority of office, will require resolute determination on the part of all who are concerned with the image of the profession as it is and who have a vision of what it might become. Nevertheless, it is a problem which must be squarely faced if we are to avoid a situation in which the promise inherent in faculty status and a truly professional working environment becomes, in the end, a mess of pottage.

H. William Axford 